\title{
Nanotechnology: A boon in cancer therapy: Review
}

\author{
Sonia Sangwan ${ }^{1 * a n d ~ R a m a n ~ S e t h}{ }^{2}$ \\ ${ }^{1}$ Ph.D, Research Scholar, Dairy Chemistry Division, ICAR- NDRI, Karnal-132001, India \\ ${ }^{2}$ Principal Scientist, Dairy Chemistry Division, ICAR- NDRI, Karnal-132001, India
}

Received: 26 August, 2020

Accepted: 08 January, 2021

Published: 09 January, 2021

*Corresponding author: Sonia Sangwan, Ph.D, Research Scholar, Dairy Chemistry Division, ICAR- NDRI, Karnal-13200, India,

E-mail: soniasangwanera03@gmail.com

Keywords: Cancer; Neo-angiogenesis; Nanoparticles; Leaky tumor vasculature

https://www.peertechz.com

\section{Check for updates}

\begin{abstract}
In cancer, there is uncontrolled cell division, which results in invasion and metastasis. Carcinomas are a significant cause of mortality worldwide. Recently, radiotherapy and chemotherapy are the primary treatment measures that are being used to destroy cancer cells. However, these modalities kill normal cells of the body, along with the destruction of cancer cells. This non-specific action is harmful to the whole body, which results in the loss of hairs, anemia, and weakness in the body. Pathological features of tumors and their abnormal neo-angiogenesis also reduce the efficiency of conventional cancer treatment. Nanoparticles (NPs) have been considered outstanding cancer-targeting vehicles due to their small size, ability to load various drugs and large surface area, and increased absorption of conjugates. They are designed and developed to take advantage of a malignant tumor's morphology and characteristics, benefits of leaky tumor vasculature, specific cell surface antigen expression, and rapid proliferation. The recent nanoscale vehicles include liposomes, polymeric nanoparticles, magnetic nanoparticles, dendrimers, and nanoshells; lipidbased NPs have been used as conjugates.
\end{abstract}

\section{Introduction}

There is an irregular and uncontrolled cell division in cancer and is accompanied by an invasion of local tissues and metastasis in distant organs [1]. Cancer is the foremost cause of death despite advanced treatment modalities. [2]. In the present era, radiotherapy and chemotherapy are the primary treatment modalities to eradicate solid tumors. However, chemotherapy harms normal cells also along with cancer cells. $[3,4]$. The most usually used chemotherapeutic agents, such as paclitaxel and doxorubicin, kills normal rapidly dividing cells in the body along with cancer cells due to the non-selective cytotoxic effect [5].

Pharmaceutical nanotechnology is a recent technology being used to study the structure,property, and behavior of materials under several hundred nanometers in size [6]. Nanotechnology can solve the problems of current chemotherapeutic agents due to its large surface area in nanosize technology. The nano vehicles with sizes $(10-200 \mathrm{~nm})$ are ideal for intracellular endocytic uptake and high drug loading. Thus, it can kill the tumor tissues in a more precise way [2,7]. These artificially synthesized nanomaterials can be used to attain safe and effective cancer treatment due to higher therapeutic efficacy because of the high chemotherapy drug load.Nanoparticle anticancer drug delivery system is beneficial in intracellular infiltration and hydrophobic solubility. Nanotechnology affects drug circulation time, reduces non-specific uptake, and decreases the toxic effect of anticancer drugs. They act specifically against tumor cells and spare normal cells.

Recently, the synthesis of multifunctional theragnostic nanosystems is being done, which can diagnose cancer and screen therapeutic response by imagining the body's tumor legions $[8,9]$. Soon, the combination of nanotechnology and biological sciences will transform the whole concept of cancer management. This review highlights the ideas of the drug carrier mechanism of nanoparticles, tumor neo-angiogenesis, and enhanced permeability and retention.

\section{Role of Nanotechnology in tumor management by affec- ting its physiology}

Vascular endothelial pores, heterogeneous blood supply, and heterogeneous architecture are physiological obstacles in cancer treatment. Drug delivery to cancer tissue is an excellent task. In the past, anticancer drugs used to affect cancer cells and normal cells of the body and thus had significant side effects. Nanoparticles have multifunctional character and useful in targeted drug delivery in cancer tissue, and normal 
body cells are spared. Nanoparticles can efficiently avoid the immune system and actively target tumors by carrying attached ligands on their outer surface. These ligands can identify and fix with receptors on tumor cells' bodies. A high amount of the anticancer drug enters the tumor cell. This enhances the effectiveness of the treatment and decreases the toxic effects on adjoining normal tissues. Thus, nanotechnology can help kill a tumor, sense pathophysiological defects in tumor cells, locate the presence of tumors due to imaging ability, and transport the therapeutic drugs to tumors depending upon tumor characteristics. Nanoparticles carrying anticancer drugs can respond to external triggers to release the anticancer drugs, document the tumor response, and identify residual tumor cells [10].

\section{Angiogenesis of cancer}

There is always neo-angiogenesis from the tissues' pre-existing vascular network during inflammation, tissue regeneration, and tumor cell proliferation. Excessive or abnormal angiogenesis is common cancer $[11,12]$. Due to the rapid growth of tumors, they require a fast microvascular network for their development. Due to the hypoxic microenvironment, pro-angiogenic factors like Vascular Endothelial Growth Factor (VEGF) in tumor get stimulated [13,14]. Vascular endothelial growth factor (VEGF), also named as Vascular Permeability Factor (VPF), has been shown to excite the proliferation, migration, and invasion of endothelial as shown in Figure 1a [15]. Due to the rapid formation of newer vessels, vessels' endothelial lining is not perfect, and there remains a gap between the endothelial lining of the new, rapidly developing vasculature. So, VEGF enhances microvessels' permeability and causes rapid and precise extravasation of plasma proteins in tissue. From leaky blood vessels, endothelial cells and fibroblasts migrate inside and create new capillary vessels and develop the stromal tissue near the tumor lesions.This phenomenon helps in the rapid proliferation of tumor cells by neo-angiogenesis $[16,17]$. The tumor vessels have a high quantity of anionic phospholipids and proteoglycans [18], which results in increased permeability to circulating macromolecules and a higher growth rate of endothelial than those in healthy tissues. The enhanced microvessel permeability results in the formation of abnormally opened inter-endothelial junctions. The size of vascular gap openings of new vasculature of tumors is about 400 to $600 \mathrm{~nm}$ and is relatively more prominent than that in normal tissues' blood vessels. Due to the large size gap in tumor vessels, the nanostructured materials of similar size can be used to enter into leaky tumor vasculatures and thus precisely deliver the loaded anticancer nanoparticles to the tumor tissues as shown in Figure 1a and Figure 1b.

\section{Role of enhanced permeability in cancer drug delivery}

Polymeric micelles and liposomes are NPs which carry the chemotherapy and leak into tumor tissue through the gaps in the vasculatures of the tumor and accumulate in tumors. This phenomenon is now known as the "enhanced permeability and retention (EPR) effect." Itis an essential phenomenon for the action of the anticancer drug on cancer cells. Angiogenic tumor vessels develop big gaps between the adjacent vascular endothelial cells due to rapid neo-angiogenesis and nano vehicles containing anticancer drugs that can enter the tumor through these gaps in leaky tumor vasculatures, as shown in Figure 2. As there are no lymphatic vessels in tumor tissue, these nano vehicles are not drained and collected in the tumor tissues and thus act for a more extended period due to stasis. There is enhanced action of drugs on cancer cells with minimum drug toxicity [19].This EPR phenomenon is for tumor tissues, not for the average healthy tissue in the neighbourhood of cancer. EPR is enhanced by various vascular mediators, such as angiotensin II (AT-II), bradykinin, prostaglandin, and Nitric Oxide (NO) [20]. There is increased systemic blood pressure and increases blood flow volume, which enhances

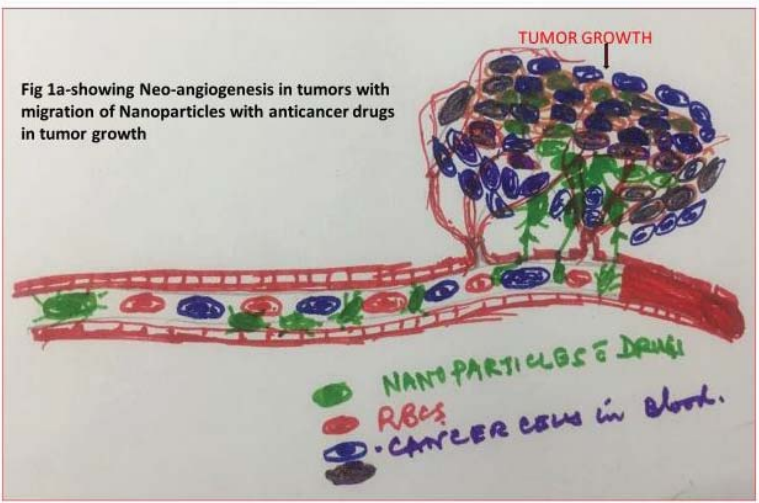

Figure 1a: Showing Neo- angiogenesis in tumors with migration of Nanoparticles with anticancer drugs in tumor growth.

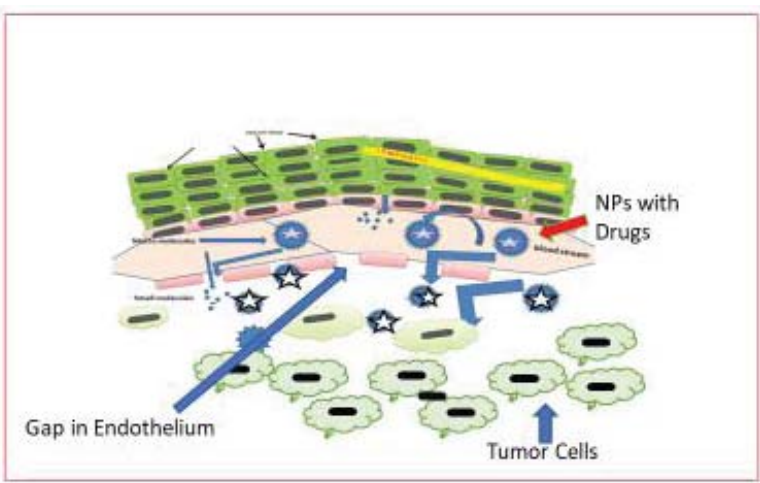

Figure 1b: Tumor Vasculature and leakage of NPs with chemotherapy in Tumor tissue.

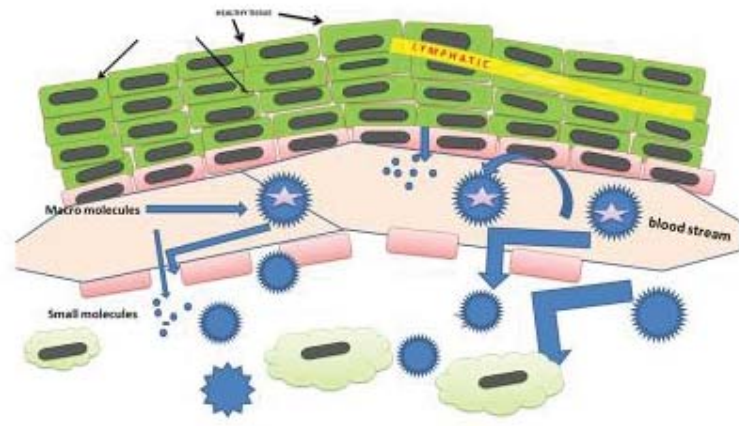

Figure 2: Enhanced Permeability Tumor Vasculature and retention of NPs with chemotherapy in Tumor tissue.

Citation: Sangwan S, Seth R (2021) Nanotechnology: A boon in cancer therapy: Review. Int J Nanomater Nanotechnol Nanomed 7(1): 001-006. 
the extravasation of NPs in tumor tissues due to the action of AT-II.AT-IIs affects contraction of the smooth muscle layer surrounding the capillary vessels.

\section{Role of nanomaterials in drug delivery in tumors}

The nanomaterials provide many unique advantages that are not accessible with other straight anticancer treatments.

First, nanomaterials own a small size similar to biological macromolecules such as peptides, proteins, and nucleic acids, as shown in Figure 3. In measurement, they are many times smaller than the size of a single cancer cell. There is a high intracellular uptake of nanomaterials due to the small size and similarities to biomolecules, and thus can be used for cancertargeted drug delivery [22]. Furthermore, the intracellular nanomaterials react with the biomolecules involved in cancer survival and proliferation [23]. More significantly, nanomaterials can protect themselves from the vascular barriers and biological defence systems of the body. Circulating body macrophages engulf these micro-sized particles comparable in size to those of microbes and thus result in fast clearance of the microparticles from the bloodstream by the reticuloendothelial defence mechanism [19,24]. Well-synthesized nanomaterials of the controlled size can gain entree to many parts of the body via the circulating system, thereby increasing the chances to carry drug load precisely to the tumors.

Second, owing to their enormous surface area relative to their total volume, nanomaterials can carry many therapeutic agents. Due to large surface area, a small size polymeric nanoparticle can carry approximately 2,000 drug molecules [25] in comparison to polymer-drug conjugate, which can carry only nine drug molecules [26]. Such a high drug loading capacity of nanomaterials is advantageous for achieving significant therapeutic efficacy in cancer therapy. Additionally, NPS offers a chance of surface modification with several targeting moieties (such as small molecules, peptides, or antibodies) for significant cancer penetration. Recently scientists have proved that the multiple attachments of a targeting ligand significantly enhance the ligand-functionalized nano vehicles' intracellular uptake in the specific cancer cells. This occurs due to the multivalent binding to the cell-surface receptors [27]. Hence a nanocarrier system with several targeting ligands can easily be used for specific uptake by the targeted tumor cells.

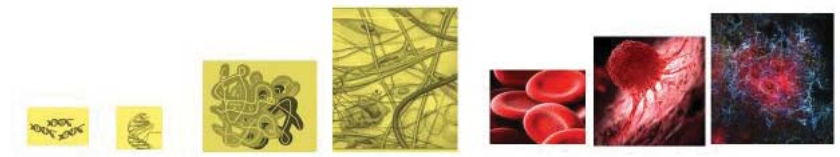

\begin{tabular}{lllllll} 
RNA & DNA & Protein structure & Matrix & RBC & Cancer Cell & Cancer Tissue \\
$1 \mathrm{~nm}$ & $1 \mathrm{~nm}$ & $10 \mathrm{~nm}$ & $100 \mathrm{~nm}$ & 1 micro m & 10 micro m & 100 micro m \\
\hline
\end{tabular}

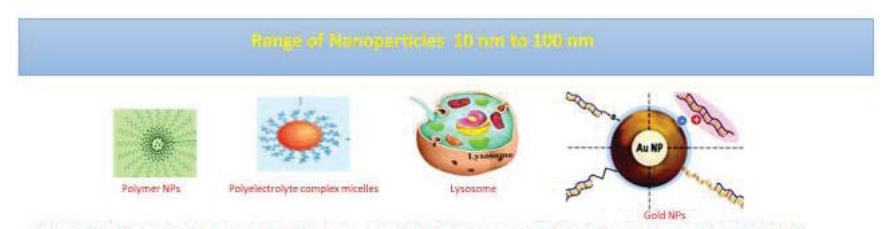

Figure 3: A schematic diagram displaying several important biological systems and artificially engineered nanomaterials in a wide range of sizes.
Paclitaxel is a water-insoluble anticancer drug [28], so great difficulties are preparing its stable solution for effective anticancer therapy [29]. The nanovesicles, such as polymeric micelles and liposomes, bind firmly with such insoluble anticancer drugs. The bioavailability and therapeutic efficacy of these drugs get improved due to encapsulation in these nano vehicles. Compared to these small molecule drugs that are cleared rapidly by renal clearance, nano vehicle-incorporated drugs stay longer in the bloodstream. A sufficient quantity of drugs can reach the target tissue [30]. As the nano vehicles can firmly compress cytotoxic drugs in the interior, they have high levels of power over drug toxicity and release profiles, thus reducing drugs' toxicity to healthy tissues. They also protect anticancer drugs from premature metabolic degradation. A new nanomaterial class response to external triggers like temperature, $\mathrm{pH}$, and light can release anticancer drugs in the specific tumor for better efficacy $[31,32]$.

The new nanosystems like polymeric micelles, polyelectrolyte complex micelles, liposomes, dendrimers, nano-emulsions, and nanoparticles are shown in Figure 3.

Polymeric micelles have hydrophilic and hydrophobic segments in aqueous solution [7] and are useful carriers for water-insoluble anticancer drugs like paclitaxel camptothecin to enhance their efficacy. The hydrophilic shell layer of polymeric micelles helps to target cancerous tissues via the EPR effect. This hydrophilic shell layer protects the combined drugs from degradation by enzymes and protects from macrophages uptake. This hydrophilic layer of nano vehicles delays the clearance by kidneys, and thus drugs stay in the bloodstream for a more extended period and kill cancerous tissues effectively [33].

\section{Polyelectrolyte complex micelles}

(Shown in Figure 3) are new nano vehicles that are usually formed by the reaction between anionic macro-molecules and the di-block copolymers and are used for efficient delivery of charged therapeutic agents [34]. The polyelectrolyte complex micelles are spherical and have an inner core and a hydrophilic outer shell layer. The polyelectrolyte complex micelles can deliver various bioactive macromolecules via the intravenous or intracellular route [35]. Moreover,the different structures and compositions can be used to make them applicable to a wide range of biopharmaceutical applications [6].

\section{Liposomes}

(Shown in Figure 3) are spherical with two layers, inner aqueous compartment and outer lipid materials, and are useful for anticancer drug delivery. They have high drug loading capacity and carry water-soluble drugs into their aqueous interior and water-insoluble anticancer drugs into the hydrophobic lipid layer [30]. As liposomes are composed of naturally-derived phospholipids, they are biocompatible with the body and cause minimum antigenic, allergic, and toxic reactions [36]. They are capable of delivering high loads of anticancer drugs to intracellular compartments of tumor cells. Macrophages in the reticuloendothelial system can engulf

Citation: Sangwan S, Seth R (2021) Nanotechnology: A boon in cancer therapy: Review. Int J Nanomater Nanotechnol Nanomed 7(1): 001-006. DOI: https://dx.doi.org/10.17352/2455-3492.000037 
liposomes due to their large size (50-400 nm). Thus, they can clear them fast and avoid that; they can be incorporated with Polyethylene Glycol (PEG) as an outer layer. This protecting layer prolongs the plasma half-life of liposomes and thus protects them from macrophages. Therefore anticancer drugs stay for a more extended period in the bloodstream, and tumors and act more effectively [19].

\section{Polymer nanoparticles}

(Shown in Figure 3) are positively charged lipid-based nanoparticles. They activate strong immune responses when injected into the body. A polymeric nanoparticle is stable and non-photo toxic to the human body. The cytotoxic drugs are loaded into the lipid matrix of polymer nanoparticles taken up by endothelial cells of the tumor's neo-angiogenic blood vessels. Thus, there is a higher concentration of anticancer drugs in cancer tissue. The photosensitizer is released from the nanoparticle inside the tumor cells, and this irradiation with visible light results in the cell-specific killing of several cancer cell lines [37].

\section{Gold nanoparticles}

(Shown in Figure 3)are the most commonly used nanoparticles for diagnostics and drug delivery. Colloidal gold's unique chemical properties make it a promising targeted delivery approach for drugs or gene-specific cells. Gold and silica composite nanoparticles can act as nanobullets for cancer. The magnetic nanoparticles have been used for cancer drug delivery. The use of magnetic nanoparticles in cell biology was first proposed in the early 1990s. Their use has separated cells from molecules such as proteins, peptides, and DNA. They are using Nanoparticles (NPs) for the drug delivery of anticancer agents [38]. It has significant advantages such as the ability to target specific locations in the body, reduce the overall amount of drug used, and the potential to reduce the concentration of the drug at nontarget sites resulting in fewer unpleasant side effects.

Certain types of nanoparticles showed some specific capacity to divergent Multi-Drug Resistance (MDR), a major problem in chemotherapy as tumor architecture causes nanoparticles to precisely collect at the cancer cells site. Their use as drug delivery vectors help in the localization of a massive amount of the drug load at the tumor site; thus,refining cancer therapy and reducing the harmful non-specific side effects of chemotherapeutics. Besides, the formulation of these nanoparticles with imaging contrast agents provides a very efficient cancer diagnostics system.

\section{Virus based nanoparticles}

There are a few viruses which have a natural affinity for receptors of malignant cells that could be used for nanotechnology application. The latest technology is used to develop non-infectious, engineered viral nanoparticles for multifunctional nanoscale devices for cancer treatment [39]. CPMV nanoparticles are the smallest virus that can cross intact through the stomach's hostile environment and be taken into the bloodstream via the intestines. So, CMPV nanoparticles could offer a means of administering anticancer drugs and tumor imaging agents orally rather than by injection. Thus, synthetic plant virus particles could prove useful in delivering drugs and imaging contrast agents to tumors because it is possible to attach tumour-targeting molecules to the surface of engineered viral nanoparticles and load various drug-type molecules into the interior of the virus particles. Geneticallyengineered form of the adenovirus was fixed with a human gene. When delivered into cancerous growth, the virus rapidly multiplies in the cancer cells and kills them. The new adenovirus can target and kill cancer cells selectively without harming normal cells $[40,41]$.

Multifunctionality of NPs is the main advantage in anticancer drugs therapy as follows:

1. NPs are useful anticancer drug carrier due to large surface area and high absorption rate.

2. NPs loaded with drugs can evade the immune system and cannot be taken away by macrophages. So, less dose of anticancer drugs is needed.

3. As there are no lymphatics in tumor tissue, there is no drainage of N.P.s with drugs and drugs to stay for a prolonged period in the tumor for enhanced action and decrease drug resistance and drug toxicity.

4. Nanoparticles overcome the resistance offered by the body's physiological barriers due to increased permeability because of large pores in tumor neovessels. Due to EPR, there is vast delivery and improved uptake of poorly soluble drugs in tumor tissue, and thus a large amount of drug is available to kill cancer cells.

5. These cancer drugs also affect the neo-angiogenic blood vessels, which are essential for tumor growth. These anticancer drugs decrease the neo-angiogenesis and cause hypoxia of cancer cells and, ultimately, cellular death.

6. N.P.s carrying drugs act as a photosensitizer and become highly phototoxic. Thus, irradiation with visible light results in the cell-specific killing of cancer cells.

7. Nano vehicle-incorporated drugs stay for a longer time in blood circulation as these are not cleared quickly by kidneys, which clear only low molecular weight chemo drugs.so, there is enhanced cellular uptake and drug localization.

8. Accurate and selective drug delivery to cancerous cell without interaction with healthy cells.

\section{Conclusion}

Nanotechnology is emerging as a boon for the diagnosis and treatment of cancer disease. A variety of nano vehicles such as polymeric micelles, liposomes, polymer nanoparticles, and gold nanoparticles have the unique capability for anticancer therapy due to greater cellular uptake, prolonged circulation after surface modification, and more efficient access to the

Citation: Sangwan S, Seth R (2021) Nanotechnology: A boon in cancer therapy: Review. Int J Nanomater Nanotechnol Nanomed 7(1): 001-006. 
targeted tumor site, as compared with micron-sized particles. Moreover, they can carry many therapeutic drugs due to their high surface-area-to-volume ratio, penetrate the leaky tumor vasculatures, and subsequently deliver the whole drug into tumor tissues via the EPR effect. Thus, nanoparticles deliver a proper dose of anticancer drugs selectively and effectively, sparing the surrounding healthy cells.

Although most of the technologies described above are proficient and efficient in cancer treatment, there are still safety concerns regarding nanoparticles' infusion in the human body. A future nanotechnology discovery area comprises the development of a bio-responsive, self-regulatory drug delivery system along with a possibility to obtain a controlled, regulated anticancer drug delivery that kills only cancer cells without any effect on surrounding normal cells.

\section{References}

1. Djojosubroto MW, Choi YS, Lee HW, Rudolph KL (2003) Telomeres and telomerase in ageing, regeneration, and cancer. Mol Cell 15: 164-175. Link: http://bit.ly/3bkRSGH

2. Heath JR, Davis ME (2008) Nanotechnology, and cancer. Annu Rev Med 59 251-265. Link: http://bit.ly/3s5PUjq

3. Hirsch LR, Stafford RJ, Bankson JA, Sershen SR, Rivera B, et al. (2003) Nanoshell-mediated near-infrared thermal therapy of tumors under magnetic resonance guidance. Proc Natl Acad Sci USA 100: 13549-13554. Link: http://bit.ly/3hTfDXD

4. Park JH, von Maltzahn G, Xu MJ, Fogal V, Kotamraju VR, et al. (2009) Cooperative nanomaterial system to sensitize, target, and treat tumors. Proc Natl Acad Sci USA 107: 981-986. Link: http://bit.ly/35ia8ww

5. Yoo HS, Lee $\mathrm{KH}$, Oh JE, Park TG (2000) In vitro and in vivo anti-tumor activities of nanoparticles based on doxorubicin-PLGA conjugates. $\mathrm{J}$ Control Release 68: 419-431. Link: http://bit.ly/39bmd82

6. Ferrari M (2005) Cancer nanotechnology: opportunities and challenges. Nat Rev Cancer 5: 161-171. Link: http://bit.ly/39dyGlb

7. Duncan R (2003) The dawning era of polymer therapeutics. Nat Rev Drug Discov 2: 347-360. Link: http://bit.ly/3npXAcE

8. Nie S, Xing Y, Kim GJ, Simons JW (2007) Nanotechnology applications in cancer. Annu Rev Biomed Eng 9: 257-288. Link: http://bit.ly/38pzn1W

9. Salvador-Morales C, Gao W, Ghatalia P, Murshed F, Aizu W, et al. (2009) Multifunctional nanoparticles for prostate cancer therapy. Exp Rev Anticancer Ther 9: 211-221. Link: http://bit.ly/3bll28s

10. Pathak P, Katiyar VK (2007) Multifunctional Nanoparticles and Their Role in Cancer Drug Delivery - A Review. AZojomo Journal of Materials.

11. Carmeliet P, Jain RK (2000) Angiogenesis in cancer and other diseases. Nature 407: 249-257. Link: http://bit.ly/3pXbyEH

12. Fidler IJ, Balasubramanian K, Lin Q, Kim SW, Kim SJ (2010) The brain microenvironment and cancer metastasis. Mol Cells 30: 93-98. Link: http://bit.ly/3nrlvaH

13. Bergers G, Benjamin LE (2003) Tumorigenesis and the angiogenic switch. Nat Rev Cancer 3: 401-410.

14. Kohandel M, Kardar M, Milosevic M, Sivaloganathan S (2007) Dynamics of tumor growth and combination of anti-angiogenic and cytotoxic therapies. Phys Med Biol 52: 3665-3677. Link: http://bit.ly/3ouYyG6

15. Lee H, Chung HJ, Park TG (2007) Perspectives on local and sustained delivery of angiogenic growth factors. J Bioact Compat Polym 22: 89-114. Link: https://bit.ly/3noRGsj

16. Jain RK (2001) Delivery of molecular and cellular medicine to solid tumors. Adv Drug Del Rev 46: 149-168. Link: http://bit.ly/3hVnCDA

17. Ruoslahti E (2002) Specialization of tumour vasculature. Nat Rev Cancer 2: 83-90. Link: http://bit.ly/2Ld8FRo

18. Ran S, Downes A, Thorpe PE (2002) Increased exposure of anionic phospholipids on the surface of tumor blood vessels. Cancer Res 62: 6132 6140. Link: http://bit.ly/3nyXFep

19. Peer D, Karp JM, Hong S, Farokhzad OC, Margalit R, et al. (2007) Nanocarriers as an emerging platform for cancer therapy. Nat Nanotechnol 2: 751-760. Link: http://bit.ly/3s54Lui

20. Maeda H (2010) Tumor-selective delivery of macromolecular drugs via the EPR effect: background and future prospects. Bioconjugate Chem 21: $797-$ 802. Link: http://bit.ly/38pZTIB

21. Goldberg $M$, Langer R, Jia X (2007) Nanostructured materials for applications in drug delivery and tissue engineering. $\mathrm{J}$ Biomater Sci Polym Ed 18: 241 268. Link: http://bit.ly/2Xp2H2l

22. Tang A, Kopečková $P$, Kopeček J (2003) Binding and cytotoxicity of HPMA copolymer conjugates to lymphocytes mediated by receptor-binding epitopes. Pharm Res 20: 360-367. Link: http://bit.ly/2L4Lysk

23. Mok H, Bae KH, Ahn CH, Park TG (2009) PEGylated and MMP-2 specifically dePEGylated quantum dots: comparative evaluation of cellular uptake. Langmuir 25: 1645-1650. Link: http://bit.ly/39ha6q5

24. Bartlett DW, Davis ME (2007) Physicochemical and biological characterization of targeted, nucleic acid-containing nanoparticles. Bioconjugate Chem 18 456-468. Link: http://bit.ly/3hVIP1k

25. Lee H, Lee K, Park TG (2008) Hyaluronic acid-paclitaxel conjugate micelles: synthesis, characterization, and anti-tumor activity. Bioconjugate Chem 19 1319-1325. Link: http://bit.ly/3oqnL4d

26. Hong S, Leroueil PR, Majoros IJ, Orr BG, Baker JR, et al. (2007) The binding avidity of a nano-particle-based multivalent targeted drug delivery platform. Chem Biol 14: 107-115. Link: http://bit.ly/3beYc2u

27. Lee ALZ, Wang Y, Cheng HY, Pervaiz S, Yang YY (2009) The co-delivery of paclitaxel and Herceptin using cationic micellar nanoparticles. Biomaterials 30 919-927. Link: http://bit.ly/3pYRFNt

28. Bae KH, Lee Y, Park TG (2007) Oil-encapsulating PEO PPO-PEO/ PEG shell cross-linked nanocapsules for target-specific delivery of paclitaxel. Biomacromolecules 8: 650-656. Link: http://bit.ly/3s5J02r

29. Allen TM, Cullis PR (2004) Drug delivery systems: entering the mainstream. Science 303: 1818-1822. Link: http://bit.ly/3nm6RIX

30. Lee SH, Choi SH, Kim SH, Park TG (2008) Thermally sensitive cationic polymer nanocapsules for specific cytosolic delivery and efficient gene silencing of siRNA: swelling induced physical disruption of endosome by cold shock. $J$ Control Release 125: 25-35. Link: http://bit.ly/3orp2lq

31. Rivera Gil P, Hühn D, del Mercato LL, Sasse D, Parak WJ (2010) Nano pharmacy: inorganic nanoscale devices as vectors and active compounds. Pharmacol Res 62: 115-125. Link: http://bit.ly/3nrgb8m

32. Kataoka K, Harada A, Nagasaki Y (2001) Block copolymer micelles for drug delivery: design, characterization, and biological significance. Adv Drug Del Rev 47: 113-131. Link: http://bit.ly/2Xk22ir

33. Park TG, Jeong JH, Kim SW (2006) Current status of polymeric gene delivery systems. Adv Drug Del Rev 58: 467-486. Link: http://bit.ly/35IKRla

34. Mao S, Neu M, Germershaus O, Merkel O, Sitterberg J, et al. (2006)

Citation: Sangwan S, Seth R (2021) Nanotechnology: A boon in cancer therapy: Review. Int J Nanomater Nanotechnol Nanomed 7(1): 001-006 
Influence of polyethylene glycol chain length on the physicochemical and biological properties of poly(ethylenimine)-graft-poly(ethylene glycol) block copolymer/siRNA polyplexes. Bioconjugate Chem 17: 1209-1218. Link: http://bit.ly/3oDocbq

35. Torchilin VP (2005) Recent advances with liposomes as pharmaceutical carriers. Nat Rev Drug Discov 4: 145-160. Link: http://bit.ly/3s5KzZr

36. Habeck M, writer F (2001) Cancer drug delivery is hot stuff. Drug Discovery Today 6: 754-756. Link: https://bit.ly/3bseRiW

37. Sealy C (2006) Nanoparticles target cancer cells in vivo. Nano today 1.

38. Rae S, Khor IW, Wang Q, Destito G, Gonzalez MJ, et al. (2005) Systemic trafficking of plant virus nanoparticles in mice via the oral route. Virology 224 235: 343. Link: http://bit.ly/35ID9HU

39. Kim JH, Lee YS, Kim H, Huang JH, Yoon AR, et al. (2006) Relaxin Expression From Tumor-Targeting Adenoviruses and Its Intratumoral Spread, Apoptosis Induction, and Efficacy. Journal of the National Cancer Institute 98: 20. Link: http://bit.ly/3hSluwi

40. Davis ME, Chen ZG, Shin DM (2008) Nanoparticle therapeutics: an emerging treatment modality for cancer. Nat Rev Drug Discov 7: 771-782. Link: http://bit.ly/3s7jLI8

41. Oh Y, Park TG (2009) siRNA delivery systems for cancer treatment. Adv Drug Del Rev 61: 850-862. Link: http://bit.ly/2Xn3IYQ
Discover a bigger Impact and Visibility of your article publication with

Peertechz Publications

\section{Highlights}

* Signatory publisher of ORCID

* Signatory Publisher of DORA (San Francisco Declaration on Research Assessment)

* Articles archived in worlds' renowned service providers such as Portico, CNKI, AGRIS, TDNet, Base (Bielefeld University Library), CrossRef, Scilit, J-Gate etc.

* Journals indexed in ICMJE, SHERPA/ROMEO, Google Scholar etc.

* OAI-PMH (Open Archives Initiative Protocol for Metadata Harvesting)

* Dedicated Editorial Board for every journal

* Accurate and rapid peer-review process

* Increased citations of published articles through promotions

- Reduced timeline for article publication

Submit your articles and experience a new surge in publication services (https://www.peertechz.com/submission).

Peertechz journals wishes everlasting success in your every endeavours.

Copyright: @ 2021 Sangwan S, et al. This is an open-access article distributed under the terms of the Creative Commons Attribution License, which permits unrestricted use, distribution, and reproduction in any medium, provided the original author and source are credited. 